\title{
As letras têm nomes: nome próprio e nomeação
}

\section{Beatriz Helena Martins de Almeida}

\author{
A meio caminhar de nossa vida \\ fui me encontrar em uma selva escura: \\ estava a reta minha via perdida. \\ Tomamos esse caminho escondido \\ ele e eu, para voltar ao claro mundo \\ e, sem repouso mais algum consentido, \\ subimos, ele primo e eu segundo, \\ até surgir-nos essas coisas belas, \\ que o céu conduz, por um vazio rotundo \\ saímos por ali, a rever estrelas.
}

Dante Alighieri

\section{Sobre o sentido e a referência em Frege}

Para introduzir a questão, vamos apresentar alguns pressupostos fregeanos sobre a noção de nome próprio.

Para Frege (1892, p. 116), um nome próprio é um sinal que deve designar ou se referir a um objeto determinado, de um modo determinado."Um nome próprio deve ter pelo menos um sentido, [...] senão ele será apenas uma mera sequência vazia de sons", deve ter um sentido e uma referência, que designe ou nomeie um objeto. "Assim, o nome próprio se relaciona, mediante o sentido, e só mediante o sentido, com o objeto".

Em contrapartida, o nome comum que Frege prefere chamar de "termo conceitual" também deve ter um sentido e deve ter uma referência; no entanto, a referência do nome comum deve ser um conceito. Assim, nome próprio refere-se a objeto enquanto nome comum refere-se a conceito. Portanto, se um nome próprio não pode designar um conceito, não pode exercer a função de predicado. Essa questão da não predicação é fundamental para a concepção de nome próprio em psicanálise.

Para Frege, o nome próprio é um sinal que tem como referente um objeto que tem valor de verdade (Bedeutung), e pode apresentar-se de modos diferentes, ou seja, pode abarcar variados sentidos. O Sentido (Sinn) para Frege são os modos de apresentação do mesmo objeto. 
Frege nos oferece como exemplo de nome próprio Vênus, que pode apresentar-se de modos diferentes, com variados sentidos: por exemplo, como estrela da manhã ou como estrela da tarde entre outros, tendo como referência o mesmo objeto - um corpo celeste.

Uma curiosidade é que isso nos permite entender porque Lacan (1971/2009, p. 16) diz, no seminário De um discurso que não fosse semblante, que o referente passeia, já que o mesmo planeta, enquanto corpo celeste, de manhã está em uma posição e à tarde, em outra. $\mathrm{O}$ objeto como referente também passeia nos giros de discurso, ora na posição da verdade, do Outro, do produto ou do semblante.

Ainda com Frege, em relação ao nome próprio, numa sentença $o$ "é" "tem a função do sinal aritmético de igualdade; ele exprime uma identidade" (FREGE, 1892, p. 91). Assim, a estrela matutina é Vênus. Joyce é o sinthoma. O sinthoma é o nome de identidade do falasser. A propriedade de identidade que participa do nome próprio é fundamental para pensar o nome de identidade do sinthoma no final de uma análise.

A partir desses pressupostos fregeanos, podemos inferir que a noção de nome próprio em Lacan articula-se ao objeto e não à cadeia significante, sendo, portanto, solidário à noção de letra.

\section{Acerca do traço unário como letra}

No seminário O eu na teoria de Freud e na técnica da psicanálise, Lacan (1954$55 / 1985$, p. 174) formula que "o objeto humano se constitui sempre por intermédio de uma primeira perda. Nada de fecundo ocorre para o homem a não ser por intermédio de uma perda do objeto". Nesse momento do ensino de Lacan, pode-se mesmo dizer que o simbólico funda a existência, nada há a não ser que seja nomeado.

Diz Lacan:

É nesta percepção que é evocada para o homem, a todo instante, sua unidade ideal, que, como tal, nunca é atingida e que a todo instante lhe escapa. O objeto, para ele, nunca é definitivamente o derradeiro objeto. Mas este se apresenta, então, como um objeto do qual o homem está irremediavelmente separado, e que lhe mostra a figura mesma de sua deiscência dentro do mundo - objeto que por essência o destrói, o angustia, que não pode alcançar, no qual não pode verdadeiramente encontrar sua reconciliação, sua aderência ao mundo, sua complementaridade perfeita no plano do desejo (Ibid., p. 211).

O traço unário constitui-se como a marca do apagamento do objeto, enquanto inexoravelmente perdido. É pela noção do traço unário que é possível passar da 
imagem à identificação simbólica. $\mathrm{O}$ traço, enquanto $\mathrm{S}_{1}$, constitui o sujeito como menos 1 e o faz a cada volta da repetição buscar a pura diferença, mais uma volta, mais uma volta, repetindo o traço enquanto apagamento do objeto. A cada volta é o número de sua repetição que é apagado.

Vejamos como Dunker (2002) sintetiza essa operação:

Em primeiro lugar há a operação de rastro. O rastro é "o que o objeto deixa enquanto ele se vai" [...]. Ele indica algo que não está lá. É o signo de uma ausência, como as pegadas de Sexta-feira. [...] Se um rastro que é negado materialmente não é mais um rastro, torna-se um traço ou uma letra. [...] O traço é, finalmente, equiparável a uma forma material compatível com a representação coisa e com a ideia de traço mnêmico visual. Em um terceiro tempo temos a negação do traço operada pela barra, aqui sim congruente com o recalcamento propriamente dito. Chegamos então ao significante. [...] O traço se articula pela estrutura da escrita, o significante se articula pela estrutura da língua. [...] O traço, como elemento legível, deve mostrar ao sujeito o suporte insensato de seu sintoma.

O traço, como $S_{1}$, comparece como significante puro, não ligado a outro significante; funciona como um significante no Real; portanto, tem valor de letra, letra que se escreve, se fixa. É só no terceiro tempo quando da negação do traço operada pela barra, que temos a constituição do sujeito evanescente nos intervalos da cadeia significante.

Gostaria de ressaltar, no caminho que percorremos neste texto, como vão se articulando as noções de objeto, rastro, traço, letra, $\mathrm{S}_{1}$. Um como traço unário. Um como mais uma volta. Um como número de repetição. Um de identidade.

O traço unário não pode ser nomeado, pois é pura diferença. Os sintomas, por identificação ao traço, são singularizantes. $O$ traço unário não tem uma função unificadora, mas sim uma função distintiva. A letra é o suporte material do significante. O sujeito só inventa o significante a partir de alguma coisa que já estava lá para ser lida. Assim o traço unário faz a escrita do sintoma.

\section{Nome próprio como nome do objeto}

Lacan (1954-55/1985, p. 215) diz que:

A palavra, a palavra que nomeia, é o idêntico. Não é à distinção espacial do objeto, sempre pronta a dissolver-se numa identificação ao sujeito, que a palavra responde, mas sim à sua dimensão temporal. $\mathrm{O}$ objeto num instante constituído como uma aparência do sujeito humano, um duplo dele mesmo, 
apresenta, entretanto, uma certa permanência de aspecto através do tempo, que não é indefinidamente durável, já que todos os objetos são perecíveis. Esta aparência, que perdura um certo tempo, só é estritamente reconhecível por intermédio do nome. O nome é o tempo do objeto. [...] A juntura está aí, a surgição da dimensão do simbólico em relação ao imaginário.

Podemos dizer que o nome é o tempo do objeto na medida em que lhe confere ex-sistência.

Lacan no seminário A identificação (1961-62/inédito, lição de 20/12/1961) revisita os linguistas acerca do nome próprio.

Para Russell: "um nome próprio é [...] uma palavra para designar as coisas particulares como tais, fora de toda descrição" (Ibid.).

Para Mill: "se alguma coisa é um nome próprio, é porque não é o sentido do objeto que ele traz consigo, mas algo que é da ordem de uma marca aplicada de alguma maneira ao objeto" (Ibid.).

Gardner "observa que não é tanto a ausência de sentido que importa no uso do nome próprio. [...] O que causa o uso do nome próprio [...] é que o acento em seu emprego é posto não sobre o sentido, mas sobre o som enquanto distintivo" (Ibid.).

Designação de um particular, marca e som distintivo.

Lacan define o nome próprio pela relação da emissão nomeadora com algo que é da ordem da letra, que, portanto, se escreve.

Lacan no seminário O sinthoma (1975-76/2007, p. 141) afirma que “a escrita [...] vem de um lugar diferente daquele do significante", articulando a escrita não ao significante, mas ao traço unário.

Acompanhemos Lacan (1961-62/inédito, lição de 20/12/1961), do traço à escrita:

O que vemos [sob] esta etiqueta de ideograma é algo que se apresenta como, de fato, muito próximo de uma imagem, mas que se torna ideograma na medida em que perde, em que se apaga cada vez mais este caráter de imagem. [...] Pois são, de fato, traços que saem de algo que, em sua essência, é figurativo, e é por isso que se crê que é ideograma, mas é um figurativo apagado [...]. O que fica é algo da ordem daquele traço unário enquanto funciona como distintivo, enquanto pode [...] desempenhar o papel de marca.

A característica do nome próprio é sempre mais ou menos ligada a este traço de sua ligação, não ao som, mas à escrita. [...] O que distingue um nome próprio [...] é que de uma língua para outra isso se conserva em sua estrutura, sua estrutura sonora; [...] e isso em razão da afinidade justamente do nome próprio com a marca, com a designação direta do significante com o objeto, [...] do nascimento do significante a partir daquilo de que ele é o signo. 
O exemplo de Champollion torna flagrante a dimensão da letra no que se refere à noção de nome próprio. Champollion conseguiu decifrar nos hieróglifos da Pedra de Roseta os nomes do faraó Ptolomeu e de sua esposa, Cleópatra, pois sendo nomes estrangeiros, imaginou que não poderiam estar grafados como ideogramas, mas que estariam escritos como eram pronunciados, como letras.

Lacan diz que o traço surge do objeto, e que retém do objeto sua unicidade, escrita como signo. $\mathrm{O} \mathrm{S}_{1}$ faz signo do objeto. Nas palavras de Lacan: "a função da escrita, a função do signo enquanto ele mesmo se lê como um objeto. É um fato que as letras têm nomes" (Ibid., lição de 10/01/1962).

E assim, nos diz Lacan no seminário Problemas cruciais para a psicanálise (1964-65 inédito, lição de 06/01/1965) que é no "nível do material significante que se produzem as substituições, os deslizamentos, os passes de mágica, os escamoteamentos com os quais temos a ver quando estamos na via, no traço da determinação do sintoma e de seu desenlace".

Signorelli, Sigmund, signans (assinatura), signatum (selado). Lacan (197576/2007, p. 64) demonstra que o sig de Signorelli é o signans de Sigmund Freud, que é o lugar de seu desejo, o verdadeiro lugar de sua identificação, que se encontra colocado no ponto cego do olho que não cessa de olhá-lo. Aqui se evidencia a relação do nome com o objeto pulsional.

Lacan (1964-65/inédito, lição de 06/01/1965) esclarece que:

A partir daí definiremos o nome próprio como alguma coisa que intervém na nominação de um objeto, em razão das virtudes próprias de sua sonoridade [...]. Por outro lado, no momento em que me apresento a vocês, Jacques Lacan, isso já elimina que eu seja um Rockfeller [...] ou o conde de Paris! Já um certo número de referências vêm imediatamente com o nome próprio. [...] Dizer que um nome próprio, em suma, é sem significação, é alguma coisa de grosseiramente errada!

Lacan não reduz o nome próprio como designando o "exemplar único", por meio de suas particularidades, mas sim na medida em que o indivíduo como insubstituível, pode faltar, mediante o fato de que seu nome próprio visa ao recobrimento de uma falta."O nome próprio é uma função volante, [...] ele é feito para preencher os buracos, para lhe dar sua obturação, para lhe dar seu fechamento, para lhe dar uma falsa aparência de sutura" (Ibid.). 


\section{Nome próprio como nome de identidade do sinthoma}

Soler (2009) diz que"existe uma tese em psicanálise segundo a qual o sintoma é o nome da identidade do sujeito, seu verdadeiro nome próprio. [...] Vemos que se trata de completar o patronímico com um traço que identifique uma singularidade que permita alcançar [...] o Um da identidade". Soler usa como exemplo Joyce, o artista, ou ainda Joyce, o sinthoma, também o Homem dos Ratos.

Para Soler,

O nome próprio designa o que de um ser não está identificado e não é identificável pelo significante. [...] Resta então um x. O nome próprio não é precisamente um significante que representa o sujeito, mas índice do que há nele de "impensável”, daquilo que é dele, mas não passa no significante, [...] de modo que o nome próprio é nome da coisa e não do sujeito. [...] O nome do sintoma é um verdadeiro nome de identidade, pois nomeia a partir de uma e apenas uma singularidade. [...] O nome de renome consegue [...] indexar juntos uma existência e seus traços de unicidade, enodando o patronímico à singularidade distinta. [...] Lacan [...] nomeia sintoma [...] a função que enoda e mantém juntos corpo, gozo e inconsciente. Renomear-se, então, tem sempre uma função borromeana, por meio da qual um sujeito assina com sua assinatura infalsificável (Ibid.).

Um nome se decanta de uma análise como condensador de gozo, porque marca e nomeia a vida pulsional do falasser, evidencia-se assim a passagem que Lacan faz do sujeito ao falasser. De modo contingencial, no percurso de uma análise algo é cingido do ser do sujeito. No final recolhe-se o que está desde o início: lalíngua. Ao desfiar a cadeia significante, pode o nome próprio tocar o vazio enquanto significância.

O nome próprio do sinthoma no final de análise enoda o que é da ordem do objeto, escrevendo de maneira contingente o traço, enquanto marca que faz o estilo. Cessa de não se escrever.

Diz Lacan (1975-76/2007, p. 141) “devido ao nó borromeano, dei outro suporte a esse traço unário. [...] eu o escrevo RI. São as iniciais de reta infinita. A reta infinita é o sinthoma. A reta infinita [...] é o mais simples suporte do furo".

Numa análise, escreve-se contingencialmente a letra de seu sinthoma como assinatura, nome próprio que marca uma singularidade e promove laço, novo amor. Como diz Soler (2009), “o dizer de nominação tem função borromeana”. Isso porque numa análise trata-se de desatar para enlaçar de modo inédito conforme as contingências. 


\section{0 traço no Discurso do Analista}

Lacan (1976-77/inédito, lição de 10/05/1977) no seminário L’insu que sait de l'une bévue s'aile à mourre diz "que o $\mathrm{S}_{1}$ não representa o $\mathrm{S}_{2}$, isto é, do Outro. $\mathrm{O}$ $\mathrm{S}_{1}$ e o $\mathrm{S}_{2}$ são muito precisamente o que eu designo pelo A barrado do qual eu fiz, ele próprio um significante $S(X)$. É bem assim que se apresenta o famoso inconsciente; esse inconsciente é [...] impossível de apreender". Esse inconsciente é o inconsciente Real que se escreve como $S(X)$ para evidenciar que não há relação sexual. Evidenciamento, que em francês se escreve évidemment que equivoca com esvaziamento.

Retomando a noção de nome próprio em Frege e em Lacan, podemos concluir da escrita do Discurso do Analista, que o $S_{1}$ no lugar da produção refere-se ao Um da Identidade.HádoUm, etemestatutodeletra,jáqueseencontraradicalmentedisjunto de $S_{2}$ e, consequentemente o saber apresenta-se como furo no lugar da verdade.

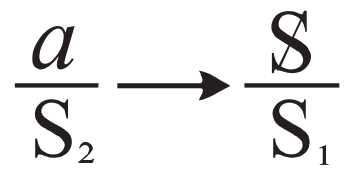

Figura 1: Discurso do Analista

Fonte: LACAN, Jacques. O seminário, livro 17: o avesso da psicanálise. Rio de Janeiro: Jorge Zahar Ed., 1992, p. 161.

Lacan demonstra que no Discurso do Analista a ligação entre $\mathrm{S}_{1}$ e $\mathrm{S}_{2}$ está rompida. Se o sujeito é o que um significante representa para outro significante, a notação do Discurso do Analista revela a destituição do sujeito ao final de uma análise e a consequente dissolução da transferência ao Outro. No lugar do semblante está o objeto a como causa. No lugar da verdade está o $\mathrm{S}_{2}$ como insabido. No lugar da produção está o $\mathrm{S}_{1}$ como significante sozinho, um significante no Real,que funciona como letra idêntica a si mesma. No lugar do trabalho talvez possamos escrever o parlêtre enquanto ser parasitado por lalíngua, destituído do Outro. E assim resta o Um fora do sentido. O Um como Um dizer. Um dizer que não há relação sexual. Um dizer que nomeia. O sinthoma, como nome próprio de identidade, permite enodar algo de Real ao laço social Imaginário Simbólico. 


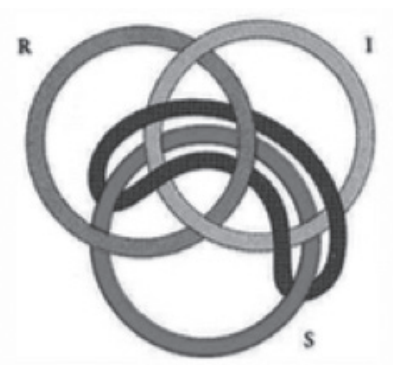

Figura 2

Fonte: LACAN, J. (1975-760 O seminário, livro 23: o sinthoma. Rio de Janeiro: Jorge Zahar, 2007, p. 21.

\section{Algumas considerações sobre nomeação na Escola}

Lacan (1976-77/inédito) começa o seminário L’insu que sait de l’une bévue s'aile à mourre retomando a identificação ao traço unário, que foi tema de seu seminário A identificação, quinze anos antes.

Renova a crítica ao final de análise como identificação ao analista praticada pelas análises didáticas no seio da IPA. Pergunta-se, então, se o final de análise seria "identificar-se ao seu inconsciente", o que refuta, pois o inconsciente resta, para concluir que trata-se de identificação ao sintoma, "savoir y faire com seu sintoma está aí o fim da análise” (Ibid., lição de 16/11/1976).

Retomando a noção de nome próprio em Frege, Lacan utiliza as letras RSI para se nomear, RSI, a heresia lacaniana, lembrando que RSI já estava lá desde 1954:

Fundar um nome próprio é uma coisa que faz sobressair um pouquinho o nome próprio de vocês. O único nome próprio em tudo isso é o meu. A extensão de Lacan ao Simbólico, ao Imaginário e ao Real [...] há datas, eu enunciei o Simbólico, o Imaginário e o Real em 54, eu intitulei uma conferência inaugural com estes três nomes tornados, em suma, por mim, o que Frege chama nome próprio (Ibid.).

Na lição de 11 de janeiro de 1977, Lacan joga com a expressão l'âme-à-tiers (alma em terços) referindo-se ao nó borromeano Real, Simbólico e Imaginário. L'âme à tiers faz homofonia com à la matière, matéria que refere-se à letra como suporte material do significante e com âme: AME. ${ }^{1}$

Assim, é pela letra que baseamos as nomeações no âmbito da Escola. $\mathrm{AE}^{2} \mathrm{e}$ AME são letras, e podem ser tomadas como funções. Como letras, estão referi-

1 Analista Membro de Escola.

2 Analista de Escola. 
das ao traço, ao traço unário, e não ao significante. Radicalmente, espera-se que cada AE, cada AME, seja Um, em seu estilo, proveniente do traço que faz marca, e lhe confere um nome no bojo da Escola. Diz Lacan, pela lógica do não todo: "o único traço comum, o traço que eu disse unário, ele se conforta do Um. Há do Um. Eu o repeti há pouco para dizer que há do Um e nada do outro" (Ibid., lição de 10/05/1977). Única garantia de varité, neologismo que conjuga verdade e variedade, que garante o reconhecimento das singularidades, como marca de diferença absoluta dos analistas que participam de uma experiência de Escola. Um. Mais-um. Mais-um...

AE e AME como letras não admitem predicação, o que decide pela nomeação - seja pela transmissão no dispositivo do passe ou seja pela indicação e reconhecimento de alguns outros - só pode ser cingido no um a um da experiência, portanto de maneira contingencial; quando acontece, faz-se avançar a psicanálise um tiquê a mais. Em boa hora.

\section{Referências bibliográficas}

DUNKER, C. I. L. Uso clínico da noção de traço unário. Revista Acheronta, 2002. Disponível em: http://www.acheronta.org/acheronta18/dunker.htm. Acesso em: 29 maio 2017.

FREGE, G. Lógica e filosofia da linguagem. São Paulo: Cultrix, 1978.

LACAN, J. (1954-55) O seminário, livro 2: o eu na teoria de Freud e na técnica da psicanálise. Rio de Janeiro: Jorge Zahar Ed., 1985.

. (1961-62) O seminário: a identificação. Inédito.

. (1964-65) O seminário, livro 12: problemas cruciais para a psicanálise. Inédito.

. (1971) O seminário, livro 18: de um discurso que não fosse semblante. Rio de Janeiro: Jorge Zahar Ed., 2009.

. (1975-76) O seminário, livro 23: o sinthoma. Rio de Janeiro: Jorge Zahar Ed., 2007.

. (1976-77) O seminário: l'insu que sait de l'une bévue s'aile à mourre. Inédito.

SOLER, C. Os nomes da identidade. 2009. Disponível em: http://www.uva.br/trivium/ edicaol/conferencia/os-nomes-da-identidade.pdf. Acesso em: 29 maio 2017. 


\section{As letras têm nomes: nome próprio e nomeação Letters have names: proper name and nomination}

\section{resumo}

Este artigo procura estabelecer uma relação entre nome próprio, traço unário, objeto, letra e sinthoma, num recorrido de alguns seminários de Lacan, desde o Seminário 2, passando pelos Seminários 9, 12, 23 e 24, articulados à teoria do nome próprio em Frege. Conclui que o nome próprio do sinthoma no final de uma análise pode enodar o que é da ordem do objeto, escrevendo de maneira contingente o traço, enquanto marca, que cessa de não se escrever. Buscou-se articular, também, algumas considerações acerca do discurso de analista e das nomeações no âmbito da Escola.

\section{palavras-chave:}

Lacan;nome próprio; objeto; letra; traço unário; sinthoma.

\section{abstract}

By going through some of Lacan's seminars, especially Seminars 2, 9, 12, 23 and 24 , this article aims to establish a correlation among proper name, unary trait, object, letter and sinthome, articulated to Frege's theory of the proper name. As a conclusion, it is established that the proper name of the sinthome in the end of an analysis can knot the object by writing in a contingent manner the trait as a mark that ceases from not writing itself. It also tries to articulate some considerations about the analyst discourse and the appointments within the School.

\section{keywords:}

Lacan; proper name, object, letter, unary trait, sinthome.

\section{Recebido:}

25/05/2017

\section{Aprovado:}

21/06/2017 